Conclusions This pilot study served as model to other schools, governments and organisations working to improve road safety. The project identified areas at risk, brought in behavioural changes, thus effectivenes of the interventions. This project can be effective and adapted for benefit of children globally.

\section{PEDESTRIANS AT HIGHEST RISK IN PAKISTAN}

${ }^{1}$ Muhammed Navid Tahir, ${ }^{2}$ Ali Hammad Akbar, 'Ahsan Kayani, 'Saif Al Ramadhani, ${ }^{1}$ Narelle Haworth, ${ }^{1}$ Mark King, ${ }^{3}$ Rizwan Naseer. 'Queensland University of Technology (QUT), Centre for Accident Research and Road Safety - Queensland (CARRS-Q), Australia; ${ }^{2}$ University of Engineering and Technology, KICS Lahore, Pakistan; ${ }^{3}$ Punjab Emergency Service (Rescue 1122), Lahore, Pakistan

\subsection{6/injuryprev-2016-042156.855}

Background Road crashes and injuries constitute a significant public health issue in Pakistan. Growing urbanisation and motorization trends, traffic violations, encroachments and lack of road safety awareness have placed pedestrians at highest risk in Pakistan. A recent study found that pedestrians constituted 53\% of the reported fatalities in Islamabad, Pakistan during 2008 to 2010. Similarly, Road Traffic Injury Research and Prevention Centre recorded 1,130 road fatalities in Karachi during 2013, wherein 379 (33.5\%) were pedestrians. The current research would be the first large scale study in the country that presents existing pedestrians safety scenario in Pakistan.

Methods Retrospective analysis of Rescue 1122 (an emergency service in Pakistan) crash data for last two years period (July 2013- June 2015) was conducted. Data were collected from 37 major cities of Province Punjab.

Results Rescue 1122 attended 407,628 road crashes across Punjab during the study period, wherein 76,737 pedestrians were injured. Of the total 5,317 fatalities, about 30\% $(n=1,577)$ were pedestrians, and $80 \%$ of them were males. Maximum pedestrian injuries 19,916 (26\%) were reported in Lahore, followed by 12,285 (16\%) in Faisalabad and 4,876 (6\%) in Gujranwala. Motorcycles (59\%), trucks (10\%) and cars $(9 \%)$ were the major colliding vehicles with pedestrians. Whilst, speeding (42\%), careless driving (32\%) and wrong turn (12\%) were the major crash contributing factors.

Conclusions Pedestrians are at highest risk in Pakistan. Speeding, careless driving, disregard of right of way, encroachments and lack of road safety awareness amongst all road users are the major factors behind increasing road crashes and pedestrians' vulnerability in Pakistan. Road crashes are not being dealt as a significant issue in Pakistan. Sustainable efforts on the part of government, transport organisations, law enforcers, community and media are required. School road safety education is also vital in this view.

\section{COMPARATIVE ANALYSIS OF ROAD ACCIDENTS BY GENDER IN EUROPE}

${ }^{1}$ Alexandra Laiou, ${ }^{1}$ Katerina Folla, ${ }^{1}$ George Yannis, ${ }^{2}$ Robert Bauer, ${ }^{2}$ Klaus Machata, ${ }^{2}$ Christian Brandstaetter, ${ }^{3}$ Pete Thomas, ${ }^{3}$ Alan Kirk. ${ }^{1}$ National Technical University of Athens (NTUA), Greece; ${ }^{2}$ Austrian Road Safety Board (KFV), Austria; ${ }^{3}$ Loughborough University, UK

10.1136/injuryprev-2016-042156.856

In 2013, 26.090 people were killed in road accidents throughout the EU, approximately 6.200 females and 19.800 males. Females account for $51 \%$ of the total EU population, but only $24 \%$ of all road fatalities.

The objective of this research is the analysis of basic road safety parameters related to road users' gender in the EU countries, by the use of the EU CARE database with disaggregated data on road accidents and of other data sources such as Eurostat. Time-series data on road accident fatalities by gender from 28 EU countries over a period of 10 years (2004-2013) are correlated with basic safety parameters, such as age, road user type and transport mode. Data from the EU Injury Database are also used to identify injury patterns and improve the assessment of injury severity and additional insight into accident causation for road users by gender is offered through the use of in-depth accident data from the EC SafetyNet project Accident Causation System (SNACS).

In all EU countries, road fatalities decreased between 2004 and 2013 for both females and males. Besides the trends of that period, the proportion of male road fatalities did not change significantly. Amongst EU countries a slight tendency for male proportions to be higher in south is noted. Additionally, the ratio between male and female fatalities increases with age, reaches a peak between the ages of 30-44 and then falls, which reflects a specific gender development in the travel behaviour of men and women in Europe. As regards the road user type, the proportion of passengers' or pedestrians' fatalities is higher for females than the males, while the opposite is true for drivers.

The results of the analysis allow for an overall assessment of the gender-differentiated safety level in the European road network, providing thus useful support to decision makers working for the improvement of safety in the European road network.

\section{CHARACTERISTICS OF ROAD ACCIDENTS WITH YOUNGSTERS IN EUROPE}

Katerina Folla, George Yannis, Alexandra Laiou. National Technical University of Athens, Greece

10.1136/injuryprev-2016-042156.857

Background Youngsters, defined as those who are between 15 and 17 years old, comprise a road user group that exhibits high risk rates due to different causes from other age groups. This age corresponds to the learning of autonomy and more particularly of access to different means of transport. In 2013, around 630 persons aged 15-17 years old were killed in road accidents in the EU, constituting almost $2,5 \%$ of all road accident fatalities for that year.

Methods The objective of this research is the analysis of basic road safety parameters related to young people aged 15-17 years old in the EU countries, by the use of the EU CARE database with disaggregated data on road accidents and of other data sources such as Eurostat. Time-series data on road accidents involving youngsters from $28 \mathrm{EU}$ countries over a period of 10 years (2004-2013) are correlated with basic safety parameters, such as gender, road user type, transport mode, road type, seasonality and day of the week. Data from the EU Injury Database are also used to identify injury patterns and improve the assessment of injury severity.

Results At this age, youngsters are beginning to gain access to driving motorised vehicles and especially motorised two-wheelers. As a result, motorised two-wheelers' share is much higher for 15-17 year olds than for the other age groups. Moreover, girls killed in road accidents were more likely to be killed as 
passengers than the boys and much less likely to be killed as drivers. As regards the type of road, in 2013 most youngster fatal road accidents occurred on rural roads. Finally, the 15-17 year olds are more likely to be killed in road accidents during spring and summer, as well as during weekends, than the whole population.

Conclusions The results of the analysis allow for an overall assessment of the youngsters safety level in the European road network in relation to the younger or older road users, providing thus useful support to decision makers working for the improvement of safety in the European road network.

\section{AUTOMOBILE MANUFACTURERS, ADVERTISING AND TRAFFIC SAFETY: CASE STUDY FROM INDIA}

Abhaya Jha, Dinesh Mohan. Indian Institute of Technology - Delhi, New Delhi, India

\subsection{6/injuryprev-2016-042156.858}

Background The first crash tests of five brands of the most popular small cars from India were released by Global NCAP in early 2014 showing that very unsafe cars are being marketed in India. This prompted an in-depth look into the advertisings behind the vehicles sold in India and their role in promotion of safety features

Methods We surveyed the print advertisements and TV commercials for safety content, and the pricing policy for offering safety technology, of six major automobile manufacturers of India. The observations were coded on a numerical scale and graded based on the safety features advertised, along with the selling price at which these features are available.

Results For TV advertisements scores ranged from 0.83 to -1.3 (on a scale of +1 to -8 ). Similarly for print advertisements scores ranged from 1.5 to 0 (on a scale of +4 to -3 ). Mainly because features like airbags and ABS were not offered in the base model of vehicles under UD \$ 12000. These safety features were available in higher end models of the same vehicle usually bundled with high end trims which had a price difference of US \$ 1500-2000 from the base model. As a positive sign though most TV commercials showed adult passengers wearing seat belts and children were usually shown in the backseat.

Conclusions Our study show that at present the Indian manufacturers are not promoting safety issues or their safety technology in any significant manner in their print advertisements or TV commercials. When safety features are offered as options they force the consumer to spend more than US \$ 1500 extra. Reliable industry sources inform us that these features should not cost more than US \$ 250 or less. The Global NCAP results inform us in a graphic manner that very unsafe cars are being marketed in India in the knowledge of the manufacturers and government officials. Therefore, it is the responsibility of the Indian Government to announce strict crashworthiness standards for cars sold in India.

\section{CHILD PEDESTRIANS' PERCEIVED RISK OF THE CROSSING PLACE}

Hagai Tapiro,Tal Oron-Gilad, Yisrael Parmet. Ben-Gurion University of the Negev, Israel

10.1136/injuryprev-2016-042156.859

Background To decide whether to cross the road, one is first required to judge whether the crossing place is safe. Young children have impoverished crossing skills manifested in lower awareness toward potential hazards, situation awareness and overall readiness for crossing. The aim of this study was to identify the environmental features that make children think a place is safe or dangerous for crossing.

Methods 24 children in three age categories (ages 7-8, 9-10, 11-13) and 12 adults viewed 41 still images of real-world roadside scenes on a wide screen, and were asked to rate each scene for safety of crossing as fast as possible using a slide bar (0100). Safety evaluation and the time to decision were recorded. Each scenario was classified by the elements of the environment: the urban area it was located in (e.g., commercial, residential), crossing location, proximity to road features (e.g., junction), road type, number of lanes, and distractors in the environment.

Results Children in all age categories estimated crossing safety mainly by obvious conspicuous features, like presence of a crosswalk, which anchored their decision. They were indifferent to certain relevant factors (e.g., number of lanes). In contrary, adults seemed to base their decision more on higher order reasoning (e.g. the duration of exposure to danger derived from the number of lanes). In general, children felt less secure when coming to cross the road, and it took them longer to reach a decision on the crossing location's safety level. When the decision was made, answers were more diverse than for adults.

Conclusions Children and adults use different strategies to estimate the safety level of a certain place for crossing. It seems that adults relay more upon sophisticated decision making processes that improves with age and experience. In contrary, children, even as old as 13 years-old, often rely on the fact that a place is designed for crossing as a guaranty for their safety.

\section{SAFE FOLLOWING DISTANCE? -DRIVER PERCEPTIONS TO HELP REDUCE REAR END ROAD CRASHES IN AUSTRALIA}

Judy Fleiter, Angela Watson, Andry Rakotonirainy, MD Mazharul Haque, Sebastien Demmel. Centre for Accident Research and Road Safety-Queensland (CARRS-Q), Queensland University of Technology, Australia

\subsection{6/injuryprev-2016-042156.860}

Background To reduce road trauma we must better understand the factors contributing to crashes. In Queensland, Australia, rear end crashes are the 3 rd leading crash type, with mild to serious injuries a likely outcome and whiplash a common injury occurrence. Road design, traffic congestion, and weather/road conditions have been implicated in rear end crashes. Human factors also play a key role, with the act of 'following too closely' being a major issue. Queensland legislation requires motorists to maintain a safe following distance between their vehicle and the one in front, although no specific information about this distance is prescribed by law for cars.

Methods To better understand perceptions of safe following distance, 495 licensed Queensland drivers (42\% male; mean age 46.2 yrs; range $16-81$ yrs) completed an online questionnaire.

Results Overall, there was wide variation in descriptions of safe following distance including time between vehicles (2 seconds $=21 \% ; 3$ seconds $=11 \%$ ), distance between vehicles (metres $=11 \%$; car lengths $=32 \%$ ); and combinations of time and distance $(1 \%)$. No one reported having received an infringement for not keeping a safe following distance, although $29 \%$ reported being involved in a crash where their vehicle hit the one 